\title{
Labor Activity Dynamics of Older Persons in the Far East of Russia
}

Ilya Nikolayevich Piontovskii*

\author{
Far East State University of Communication Lines, Khabarovsk, Russian Federation; piontovskii@mail.ru
}

\begin{abstract}
The necessity to study the labor activity of older persons in the Far East of Russia is being actualised ever more acutely due to the decrease in the ratio of the economically active population in the region, as well as due to the increase in the number of elderly people. The analysis of the older group labor activity has been presented together with the factors acting thereupon in the Far East of Russia. The labor activity of the older persons groups is definitely dependent on the outer conditions and on the factors of this social group labor potential formation and implementation, including the social/economic conditions on the whole, the social and economic policy, employment and social protection policies, etc.
\end{abstract}

Keywords: Labor Activity, Labor Potential, Life Standards, Older Persons

\section{Introduction}

Population ageing is one of the world general trends in the age structure of the population, when the share of children and young men is getting smaller and that of the elderly people is increasing. This process, stipulated by the death-rate reduction, birth-rate reduction, resulting in the fact that every next generation appears less populous than the previous one, is highly characteristic for the developed countries, but it has been spreading over other countries as well, including Russia. As a result thereof, the older persons become the fastest growing group of population. Population ageing relates to the higher load at the economically active population, to the long-term budget misbalance and to the resulting slowdown in the economy growth. Therefore the task of engaging the older persons into the labor activity is being actualized.

Realizing the labor potential of the older people is, due to the specific features of this social group, associated with many problems which get even worse under the existing conditions in some regions, such as, for instance, the Far East. Undoubtedly, the preconditions have to be established to realize the economic initiative of the older groups, to boost the labor activity. Thus the potential labor activity of the older groups comes into conflict with the conditions and the factors of its implementation.

The major issue of this study is the economic relations inconsistency, affecting the interests of the elder people, in the requirements put forward by the market system, including the labor market, toward the quality of labor and toward the labor behavior from the point of view of the degree of the labor activity, on the one hand and in the actual behavior, norms and the life standards of the older groups in society, on the other hand.

In view of the specified problem the major objective of this study is the analysis of the older group labor activity level together with the impacting factors in the Far East.

The persons from the older groups represent a distinctive social community, which special features can separate it as a stand-alone object of social and economic policy of the state. Special interest rests in the behavioral study of the working elderly persons under the conditions in some particular regions due to the insufficient knowledge of this problem. Labor activity of

\footnotetext{
${ }^{*}$ Author for correspondence
} 
the people from the older groups at the time of the market relations formation is closely and definitely related to the outer conditions and factors of this social group labor potential formation and implementation, including the social/economic conditions on the whole, the social and economic policy, employment and social protection policies, etc. However, the inner factors can bring about serious corrections to the level of the labor activity.

\section{Literature Review}

The undertaken analysis of the theoretical sources, dedicated to studying the labor activity, allows for drawing a conclusion that the investigators used different sets of indicators of both economic and social nature; different techniques to estimate the degree of labor activity (the scoring methods, for instance, the factors, the integral indices, the sociology methods).

Thus, for example, in the study under the editorship of A.A. Krylov and G.V. Sukhodolsky ${ }^{1}$ the labor activity of a man is supposed to be described by means of the following indices:

- Cyclical nature of the activity, work-rest schedule;

- Capacity for work, its dynamics for a particular person;

- Intensity of work;

- Peculiar features of the practical conditions (the conditions coming forth in the process of work). Such practical conditions as functional comfort, psychical fatigue, psychic tension, lack of motivation, emotional stress, monotony, anxiety, state of indifference are diagnosed most frequently;

- Correlation of the reproductive and the creative in the labor, the degree of excessive activity, the availability of so-called "unselfish risk";

- Specific features of self-stimulation;

- Overcoming external and internal restrictions, barriers, the evidence of volitional component, alterations to the activity when no definite results are forecast;

- Availability of innovations (developing new forms of activity).

Undoubtedly, one has to agree with V.Yu. Mamayeva ${ }^{2}$ that the undertaken studies and the proposed systems for estimating the labor activity are of definite scientific and practical interest today.

Traditionally, when social/economic science investigates labor activity, its subjective and objective sides are supposed to be specified and represented in qualitative and quantitative, subjective and objective indicators accordingly.

Objective indicators of labor activity are the indicators characterizing it by means of the labor activity results and through the behavior in the process of labor: Output, quality of work, adherence to labor and technological discipline, etc.

Subjective indicators characterize the personality mindset, the way one conceives the labor: Motivation, satisfaction; attitude toward labor, as well as the personal self-estimation of the labor activity, realization of one's own potential in the process of work. With no estimation by the subject of labor any activity is seen unaccomplished, incomplete.

However, when dealing with labor activity of the older persons groups the very set of the labor activity indicators has to be reviewed. Due to this fact the following methodology has been elaborated.

\section{Research Methodology}

The methods of qualitative and quantitative analyses of the information obtained in the course of expert interview and observation have been used in the study.

\subsection{Quantitative Methods}

The quantitative methods of investigation include the methods of obtaining the information on the object under study, which allows identifying its quantitative characteristics.

\subsection{Qualitative Methods}

Qualitative investigations are aimed at obtaining the profound, comprehensive information on the subject of study. In contrast to the quantitative methods, these ones are focused not on the statistical measurements, but rely on understanding, explanation and interpretation of the empirical data and are the source of formulating hypotheses and the productive ideas.

\subsection{Expert Interview}

To determine the directions of regulating the labor activity of the population under the conditions in the regions, particularly in the Far East, the expert interview has been undertaken. Its major purpose was to specify the problems and to justify the directions of regulating the 
labor activity of the population. The sampling is stratified in different groups.

The degree of the labor activity is operationalized in several judgments, contained in the optional answers to the questions of the questionnaire developed by the author.

The tools of the investigationincluded the questionnaire and the instruction to the interviewees. In the course of the investigation the pilot interview has been carried out, upon which the tools have been updated. Besides, the interview has been accompanied by the personal nonformal discussion on the problems, touched upon in the questionnaire, as well as by non-inclusive observation, studying expert opinions (plant managers, managers of the employment committee departments), which helped getting deeper insight into the problem and verifying the findings of the written interview.

\section{Results}

The persons from the older age group represent a distinctive social community, which special features can separate it as a stand-alone object of social and economic policy of the state. For the author of this study the particular interest rested in studying the behavior of the working people from the older groups under conditions of the labor-deficient regions due to the generally insufficient knowledge of this problem. Thus, the stated object of this study is the working people from the older population groups in the Far East of Russia.

The quantitative labor activity indicators of the older persons groups as of the social group on the whole can be represented by the indicators of the degree of their taking part in the social labor, i.e. the employment, economical activity indicators; the structure of the employed population, which shows the qualitative identification of labor resources; the effectiveness of labor in the sphere of social production etc. As the quantitative indicators of the older group labor activity one can identify the following: Older people's attitude to the role and to the standing in society, focus of their interest at the labor sphere; availability of motives, related to the content of labor activity; the level of the efforts spent for doing job at a definite work place; orientation at preserving the position, the profession; labor and professional mobility, including the correlation between satisfaction in different aspects of labor activity at a definite work place and the mindset focused at some definite actions; adaptability of life conditions; estimation of personal activity in solving the problems, focusing at one's own efforts or at the help from the others, etc.

Labor activity of the people from the older groups at the period of the market relations formation is closely and definitely related to the outer conditions and factors of this social group labour potential formation and implementation, including the social/economic conditions on the whole, the social and economic policy, employment and social protection policies, etc. However, the inner factors can bring about serious corrections to the level of the labour activity.

The objective part of the study has been provided by the plant managers ( $2 \%$ of the interviewees), by the plant department managers ( $7.5 \%$ of the interviewees), by specialists ( $22.5 \%$ of the interviewees), by clerks (29.5\% of the interviewees), by foremen (5.5\% of the interviewees), by qualified workers ( $27 \%$ of the interviewees) and by others (founders, engine-operators, interns, students - $6 \%$ of the interviewees). On the whole, 400 experts living in the Far East of Russia took part in the interview. Among the interviewed experts $41 \%$ were males and $59 \%$ females.

Age characteristics are as follows: Younger than 30$32.5 \%, 30$ to $39-26 \%, 40$ to $49-16 \%, 50$ to $59-21 \%, 60$ and older $-4.5 \%$ (Figure 1 ).

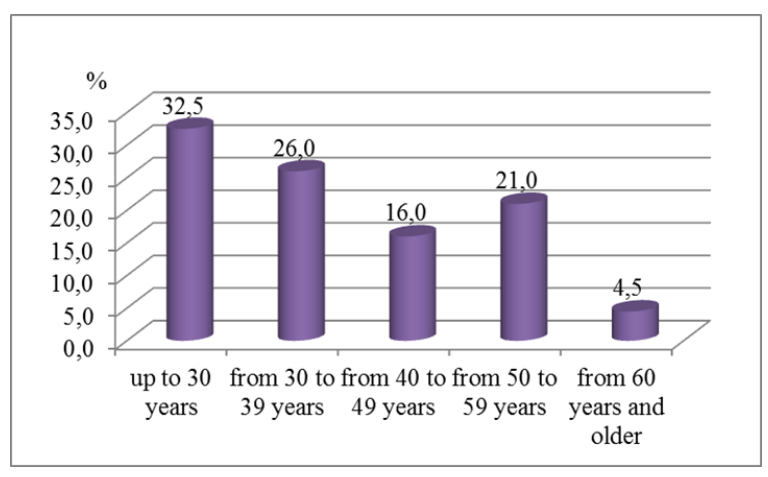

Figure 1. Age characteristics of the experts, number of the respondents.

As for the education level of the experts, the following picture is made: $3.5 \%$ of the interviewees have unaccomplished secondary education, $17 \%$ have secondary education, $24 \%$ have higher education, $18 \%$ have unaccomplished higher education and $37.5 \%$ have specialized secondary education.

Record of service of the experts as a percentage amounted to: Less than 5 years $-40.5 \%, 11$ to $20-19.5 \%, 5$ to 10 years $-17.5 \%$, more than 20 years $-22.5 \%$ (Figure 2 ). 


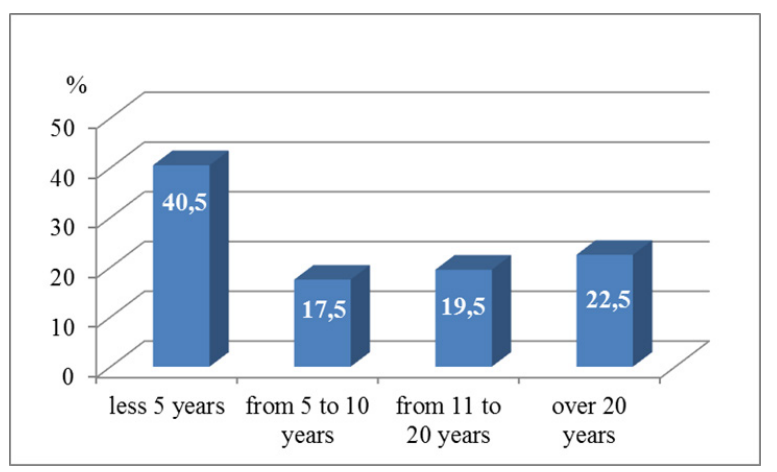

Figure 2. Record of service of the experts, the number of the respondents.

As for other social characteristics, the experts were placed as follows. Marital status: $44 \%$ are married, $34 \%$ have never been married, $18 \%$ are divorced, $4 \%$ have chosen "other".

Other family conditions were characterized as follows: $59.5 \%$ of the experts have children, $40.5 \%$ do not have children, $65.5 \%$ live together with their families, 34.5\% live alone.

Based on the results of the interview it was found that the majority of the interviewees $(68 \%)$ believe that to the modern representative of the older age group, both the work and the social standing are important and 32\% believe that the most important thing for the older age group is recreation.

As regards the willingness to resign, that is to work no longer, it appeared that $49 \%$ are not in themselves ready to resign, $25 \%$, though not ready to resign, have to adapt to the new conditions now, $19 \%$ are psychologically ready to resign, but have not changed anything in their lives so far and just $7 \%$ are completely prepared to resign and have already started changing their lifestyle. Undoubtedly, such results of the interview were influenced by the fact that the major part of the interviewees were younger than $50(74.5 \%)$.

When resigned, $76.5 \%$ of the respondents rely on themselves only, $12.5 \%$ hope for the support from relatives and friends, $10 \%$ hope for help from the state. Moreover, $27.5 \%$ are completely satisfied with their social standing, $53 \%$ are satisfied in general, but face some definite problems, $17.5 \%$ are rather not satisfied and $2 \%$ are fully unsatisfied with their social standing. Interestingly, the latest category of the interviewees was made of experts younger than 50 .

For $47.5 \%$ work is an important and interesting thing, but it must not overshadow other sides of life and 30.5\% believe that work is a source of means for existence. For
$14.5 \%$ work is the sense of life, they put into it all their efforts and abilities, notwithstanding the wages. Only $7.5 \%$ consider work to be an unpleasant necessity and should they be given a possibility, would not work at all.

The experts were asked to estimate the results of the alterations, which took place over the recent years in the pension system. Only $2 \%$ believed that these reforms brought about important positive results; in the opinion of $26 \%$, something has changed for better; $37.5 \%$ thought that the changes, which took place, did not affect the lives of the pensioners in any way; $6.5 \%$ believed that there were some changes for worse; $5 \%$ considered that these alterations in the pension system have brought about considerable negative results. It is indicative that $23 \%$ found it difficult to answer the question. In the opinion of the author, those expert estimations were influenced by the fact that it was difficult for them to estimate the pension reforms presently underway.

It was suggested that the experts should formulate the most important outcomes of the alterations in the pension system. In general, a large part of the experts were at a loss for an answer. Some have indicated that the amounts paid do not correspond with the amounts of money deducted, the average pension does not give pensioners the possibility to pay for public utilities easily, to feed normally, to buy necessary medicines; there is a drop in the pensioners' life standards. All the above mentioned negative trends are not an unimportant factor for boosting the labor activity of the pension aged people, who have to work in order to live.

When the experts answered the question 'What is the most important in the labor activity for the older persons' groups?' the following results have been obtained (Table 1).

The data of Table 1 show that the majority of experts indicated the following priorities in labor activity of the older persons groups: Convenient work pattern, work environment and remuneration.

As for the fringe benefits for the working people from older groups, most respondents, namely, $53 \%$ believe that convenient work pattern should become such a benefit, $18 \%$ specified shortened working hours, $28 \%$ chose additional days of vacation, $16 \%$ specified the necessity to be free from business trips. Within the framework of the abovementioned there are interesting answers to the question 'What would it be like if the material standing made it possible not to work?' Those who would dedicate themselves to their homes and families made up 38\%, those who would work half-day or work from home amounted to $37 \%$, those, who would continue industrial 
working out of home accounted for $19 \%$. As other optional answers the following ones have been indicated: Tourism, creative activity, self realization.

Table 1. Priorities in labor activity for the older persons groups

\begin{tabular}{lc}
\hline Optional answers & $\begin{array}{c}\text { Number of } \\
\text { answers, \% }\end{array}$ \\
\hline Convenient work pattern & 54 \\
Profession and work place prestige & 12.5 \\
Content of work, the possibility to realize & 16.5 \\
oneself & \\
Communication in the team & 29 \\
Career (growth in the office) & 12.5 \\
Professional promotion & 7.5 \\
Work environment & 55 \\
Practical application of the obtained knowledge, & 8.5 \\
education & \\
Material remuneration for work & 43.5 \\
Guarantee of the work place retention & 22 \\
Opportunity for fringe benefits (travels etc.) & 22.5 \\
Other & 1 \\
\hline
\end{tabular}

Thus, the majority of the respondents are interested in their work, notwithstanding their material standing.

When choosing the job options and the wages for the people already resigned, the majority of experts gave preference to calm and well paced jobs with small but uninterrupted wages (52\%). The option of the intensive, diverse jobs with extraordinary situations and with guaranteed level of salary has been chosen by $28 \%$. The ones who prefer earning a lot but depending on the results of their work and even with the risk of financial losses accounted for $7.5 \%$. $6.5 \%$ would prefer working half-day with lesser wages and 5.5\% would prefer not to work at all. Interestingly, two later options attracted not only the persons from the older group, but also the experts younger than 30 , which in the author's opinion, has been to a large degree stipulated by the situation, when a lot of young specialists today have developed an attitude that the government bodies are obliged to patronize over them all their lives. A notion comes to life that they should have everything done for them by others, the preconditions for glamorous and satiated life have to be provided for them. To change this situation the internal attitude and the mindset have to be modified, the understanding of life has to be altered.

It was suggested that the respondents should estimate their satisfaction with different aspects of their jobs.
Based on the results of the interview, the respondents were most of all satisfied with the pattern of work, with the relationships within the team, relationships with the management. The least of all they were satisfied with the wages, with the amounts of benefits and with the way they were distributed.

When giving an appraisal of their manifestation in the working activity, half of the experts noted that they fulfill all the obligations they are entrusted with and try not to stand out, just to work neither better nor worse than others, $35 \%$ do display initiative, creativity and try to realize themselves to the full, $7 \%$ consider that too much obligations have been imposed on them, $8 \%$ in contemporary situation do not want to work at all.

However, having said that, $36 \%$ are afraid of being left out of job altogether, $33.5 \%$ chose the answer "rather yes than no", $20 \%$ are not afraid of being left out of job and $10.5 \%$ chose the optional answer "rather no than yes".

It is interestingly that when estimating their activity in solving their own problems, $38 \%$ do solve their problems independently and actively, $55 \%$ try to do everything they can and only $2 \%$ stated that they have neither power nor means and $4 \%$ are initiative-less and wait for the problems to solve themselves with time.

The experts were also asked a question 'What would you do if you had to quit your job?' (It was suggested that they should choose not more than two options). The results are given in Figure 3.

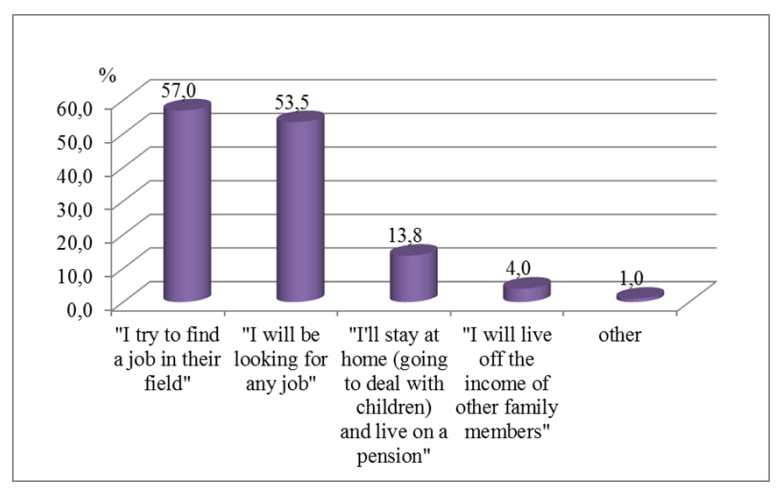

Figure 3. The choice when losing a job, $\%$ of the interviewees.

It appeared that most part of the interviewees would look for a job.

When the respondents rated the values of life on pension the following data have been obtained (Table 2).

The data show that for the majority of respondents the most valuable things in pensioned life are the following: Stability and confidence in tomorrow; independence, 
Table 2. Rating the values of pensioned life, $\%$

\begin{tabular}{|c|c|c|c|c|c|}
\hline \multirow[t]{2}{*}{ Question } & \multicolumn{5}{|c|}{ Rating } \\
\hline & $\begin{array}{l}5 \text { - most } \\
\text { significant }\end{array}$ & $\begin{array}{l}4 \text { - less } \\
\text { significant }\end{array}$ & $\begin{array}{l}3 \text { - of little } \\
\text { significance }\end{array}$ & $\begin{array}{l}2 \text { - practically } \\
\text { no significance }\end{array}$ & $\begin{array}{l}1- \\
\text { indifferent }\end{array}$ \\
\hline 1 - stability, confidence in tomorrow & 81.5 & 5 & 1 & 0 & 0 \\
\hline 2 - independence, freedom, self-sufficiency & 63.5 & 16 & 4.5 & 1.5 & 0 \\
\hline 3 - communication (with colleagues) & 38.5 & 26 & 13 & 2.5 & 1 \\
\hline $\begin{array}{l}4 \text { - social status (station in society), acknowledgement by } \\
\text { other people }\end{array}$ & 36 & 31 & 11 & 2 & 2 \\
\hline 5 - material well-being, sufficient supply of necessities & 77 & 7.5 & 1 & 0 & 0 \\
\hline 6 - interesting job & 46 & 19.5 & 9.5 & 5 & 1 \\
\hline 7 - family, staying at home & 65 & 12 & 4 & 0.5 & 0 \\
\hline 8 - power, possibility of influencing others & 6 & 15 & 19 & 18 & 20.5 \\
\hline
\end{tabular}

freedom, self-sufficiency; material well-being, sufficient supply of necessities; family, staying at home.

The experts were asked to evaluate, whether the discrimination exists at hiring the people from the older age group. At that, $40 \%$ believe that there is no such discrimination and $60 \%$ are sure of the opposite. In their opinion, the discrimination reveals itself both in refusing hiring, not withstanding the available professionalism and experience and in proposing only the low-paid positions, etc.

The respondents were asked to indicate the facts of older persons' discrimination they observe in most decisive spheres (Figure 4).

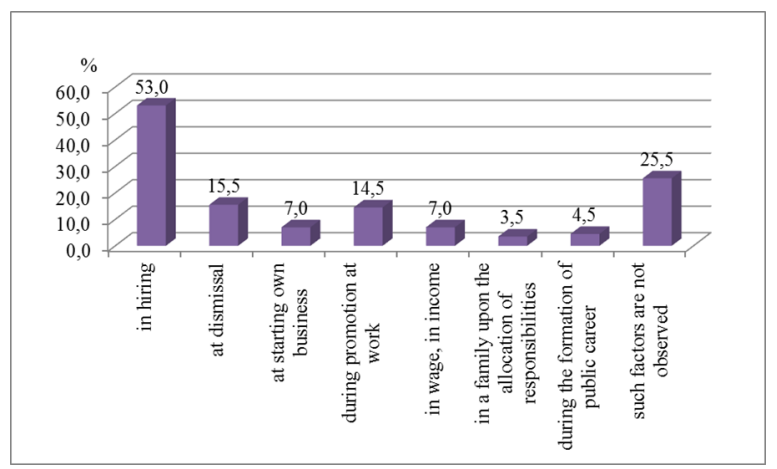

Figure 4. Facts of the older people discrimination in decisive spheres of life, $\%$ of the interviewees.

As we see, the facts of the older people discrimination are most frequently observed in hiring.

Most of the interviewed (45\%) believe that the major difficulties for the older group people's participating in managerial activities lie in the decreased capacity for management in the older age period. Yet another 18\% believe that the problems lie in general mistrust toward the pension age people and the remaining $37 \%$ are sure that the problem is a far-fetched one.

As regards the willingness of the respondents to start their own business when resigned, the following results were obtained (Table 3 ).

Table 3. Willingness of the respondents to start their own business when resigned

\begin{tabular}{lc}
\hline Optional answers & $\begin{array}{c}\text { \% of the } \\
\text { interviewed }\end{array}$ \\
\hline I am ready to start my own business and I & 18 \\
know how to do this & 19 \\
I am ready, but I don't know how to do this & 7.5 \\
I am ready, but I don't want to & 6 \\
I know the business, but I am not ready per- & \\
sonally & 26.5 \\
I have not made up my mind & 23 \\
I am not ready &
\end{tabular}

The results of the interview represented in Table 3 show that $37 \%$ are ready to start their own personal business.

There are interesting reasons, pointed out by the interviewees, which prevent people from undertaking their own businesses (Table 4).

Thus, one of the basic reasons preventing the older persons groups from undertaking their own businesses is the lack of means to start the business. This is also confirmed by the respondents' answer to the question of where the major problems lie in the elder people labor activity. Most of the interviewed (73\%) have declared material constraints, only $24 \%$ have chosen the option "lack of benefits", among other optional answers the following have been pointed out: Lack of strength for the job, lack of vacancies, health. 
Table 4. The reasons preventing people from starting their own businesses

\begin{tabular}{lc}
\hline Optional answers & $\begin{array}{c}\text { Number of } \\
\text { answers, \% }\end{array}$ \\
\hline $\begin{array}{l}\text { Organizational difficulties (documental legaliz- } \\
\text { ing etc.) }\end{array}$ & 17.5 \\
Lack of personal qualities: Initiative, intuition, & 14.5 \\
"entrepreneurial spirit" & \\
No business idea & 17.5 \\
Not prepared to run a risk & 17.5 \\
No means to start & 48.5 \\
Lack of knowledge and experience & 19 \\
I am afraid of the foul play in business & 12.5 \\
I am not interested & 12.5 \\
I am too old for business & 4.5 \\
Other & 2 \\
\hline
\end{tabular}

When the respondents estimated the qualities of an ideal worker and those of their own, the following results were obtained (Figure 5).

Interestingly, for the most part the perfect employee qualities are practically identical to those of the respondents. That is, the experts do value themselves as perfect employees.

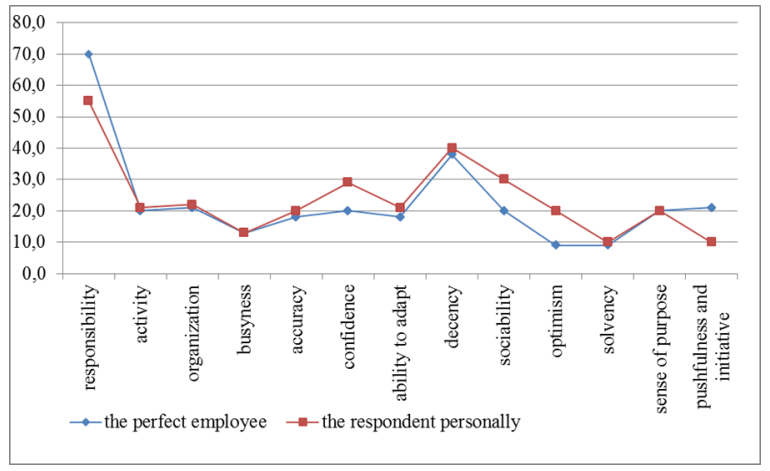

Figure 5. Respondents' evaluation of the perfect employee qualities and those of their own.

To estimate social activity of the interviewees they were proposed to choose, in which forms of protest they would agree to take part to protect their interests (Figure 6).

The data represented in Figure 6 show that the majority of the interviewed are only prepared to criticize the actions of the managers within the group of their own colleagues, friends and families by means of oral and written complaints.

When describing their material standing $17 \%$ stated that they were in want of the very necessities, $37 \%$ had just enough to cover the necessary things (food, public service payments); $40 \%$ stated that they had enough for the necessities and that they save by little for clothes, furniture, appliances; only $3.5 \%$ can afford big purchases (car, flat, country house) and 2.5\% answered that they had enough for everything.

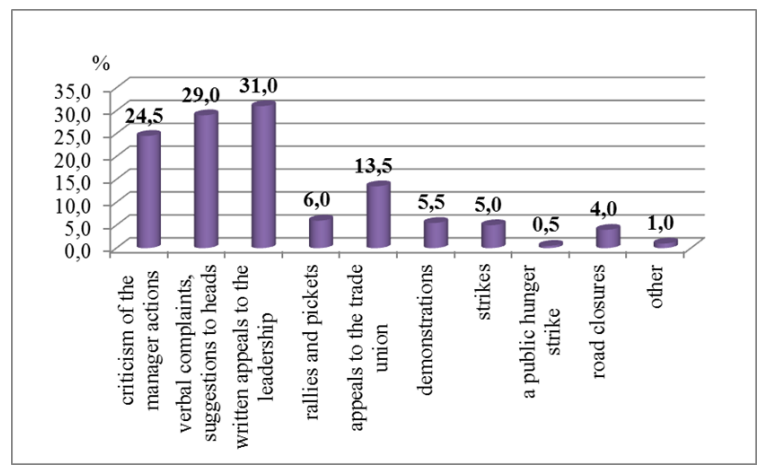

Figure 6. Forms of protest, in which the respondents would take part to protect their interests, $\%$ of the respondents.

Figure 7 shows the data on income sources of the respondents, whose basic income consists of wages and returns on shares, bonds.

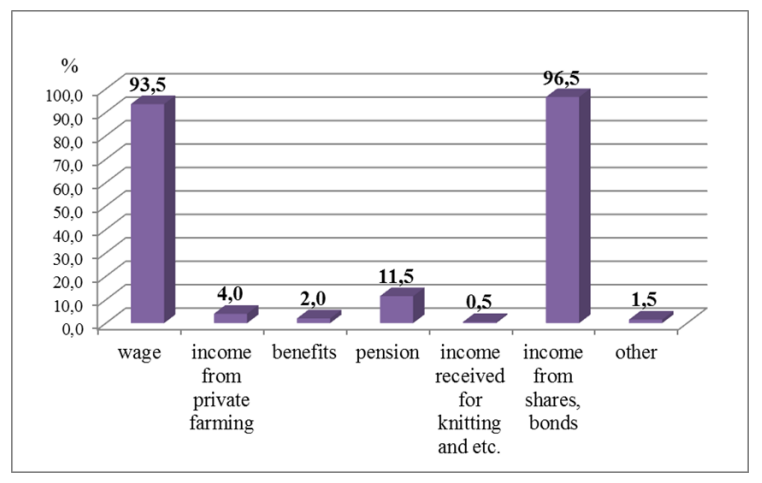

Figure 7. Data on the income sources of the respondents, $\%$ of the interviewees.

Having said that, $7.5 \%$ of the respondents believe that the general standards of pensioners' life have been considerably improved over the last ten years, 26.5\% consider that they improved only a little, $7 \%$ have chosen the answer "they got a little worse", $22 \%$ think that they are at the same level; in the opinion of other $15.5 \%$ of the interviewees they decreased considerably, $21.5 \%$ of the interviewed were at a loss for an answer. 


\section{Conclusion}

- Labor activity of the older persons is closely and definitely dependent on the external conditions and on the factors of this social group labor potential formation and implementation, including the social/ economic conditions on the whole, the social and economic policy, employment and social protection policies, etc.

- Internal factors can bring about serious corrections to the level of the labor activity.

- The degree of the older persons' labor activity is influenced by their economical, social, legal status.

- All indicators of the older persons' labor activity are interconnected and interdependent.

\section{References}

1. Krylov AA, Sukhodolsky GV (Editors). Ergonomics: The textbook Leningrad: LGU; 1988 [in Russian].

2. Mamayeva VYu. The labor participation of women in the conditions of market relations formation: $[\mathrm{PhD}$ Thesis (Economics)]. Omsk; 1999 [in Russian].

3. Bailey C. An operational framework for pension reform: Coverage under social security pension schemes. ILO; 1997.

4. Barr N. A public-private partnership in pensions: Getting the balance right. Agulnik, Ph, et al. Partnership in Pensions? Responses to the Pension Green Paper. CASE Paper. 1999 Apr; 24:30-45.

5. Barr N. Reforming pensions: Myths, truths, and policy choices. Working Paper No. WP/00/139. IMF. 2000 Aug.

6. Branco M. Pension reform in the Baltic's, Russia and other Countries of the Former Soviet Union (BRO). IMF Working Paper. WP/98/11. 1998 Feb.

7. Chand S, Jaeger A. Aging populations and public pension schemes. IMF. Washington, DC; Occasional Paper 147. 1996 Dec.
8. Clark RL, Quinn JE. Effects of pension on labor markets and retirement. Paper presented at ERISA after 25 years. A Framework for Evaluation Pension Reform, Mimeo; 1999 Sep.

9. European Commission. Confronting demographic change: A new solidarity between the generations. Green paper. Employment and social affairs; 2005.

10. Human Mortality Database: University of California, Berkeley (USA) and Max Planck Institute for Demographic Research (Germany). Data downloaded on March 6, 2010. Available from: www.mortality.org or www.humanmortality

11. Kertzer D, Leaflet P. (Editors) Aging in the past. Demography, Society and Old Age. Berkeley; 1995.

12. Lindbeck, A, Persson M. What are the gains from pension reform? Mimeo; 2000.

13. Neugarten BL. Age groups in American Society and the rise of the young old. Political Consequences of Aging. Annals of the American Academy of Social and Political Science. 1974 Sep; 415(1):187-98.

14. Piontovsky IN, Dudikova AS. Revisiting the question of resident population formation in the Far East Russia. Science and Business: Ways of Development. 2012; 4:84-9.

15. Population Reference Bureau. Older Workers and Retirement. Today's Research on Aging. Issue 12, 2008 Jun; Available from: http://www.prb.org/Home/TodaysResearch.aspx

16. United Nations Publications. The sex age distribution of the world. The 1992 Revision. New York, UN. 1993; 4-8.

17. United Nations, Department of Economic and Social Affairs, Population Division. World Population Ageing. 2007; Available from: http://wwwun.org/esa/population/publications/WPA2007/wpp2007.htm

18. United Nations. World Population to 2300. New York, UN. 2004; Available from: http://www.un.org/esa/population/ publications/longrange2/WorldPop2300final.pdf

19. Voeikov MI, Grechishnikov PV (Editors). Increasing labor activity of the masses. The Socio-economic Problems. Moscow: Economics; 1987. [in Russian]. 